\title{
Dual versus triple therapy in patients hospitalized for COPD in France: a claims data study
}

This article was published in the following Dove Press journal:

International Journal of Chronic Obstructive Pulmonary Disease

\author{
Faustine Dalon' \\ Nicolas Roche ${ }^{2}$ \\ Manon Belhassen' \\ Maëva Nolin' \\ Hervé Pegliasco ${ }^{3}$ \\ Gaëtan Deslée ${ }^{4}$ \\ Bruno Housset ${ }^{5}$ \\ Philippe Devillier 6 \\ Eric Van Ganse ${ }^{1,7,8}$
}

'Pharmacoepidemiology Department, PELyon, Lyon, France; ${ }^{2}$ Respiratory Medicine, Cochin Hospital, AP-HP and Paris Descartes University (EA25II),

Sorbonne Paris Cité, Paris, France;

${ }^{3}$ Pulmonary Department, European Hospital, Marseille, France; ${ }^{4}$ Pulmonary Department, INSERM UI250, Maison Blanche University Hospital, Reims, France; ${ }^{5}$ Pulmonary Department, $\mathrm{CHI}$ de Créteil, University Paris Est Créteil, Créteil, France; ${ }^{6}$ Department of Airway Diseases, UPRES EA 220, Foch Hospital, Paris-Saclay University, Suresnes, France; ${ }^{7}$ EA 7425 Hesper Health Services and Performance Research, Claude-Bernard University, Lyon, France; ${ }^{8}$ Respiratory Medicine, Croix-rousse Hospital, Lyon, France

Correspondence: Faustine Dalon PELyon, I I Rue Guillaume Paradin, Lyon 69008, France

Tel +33 478771024

Fax +33478778660

Email faustine.dalon@univ-lyon I.fr

\begin{abstract}
Purposes: Following a hospitalization for COPD, dual and triple therapies were compared in terms of persistence and relations with outcomes (exacerbations, health care resource use and costs).
\end{abstract}

Methods: This was a historical observational database study. All patients aged $\geq 45$ hospitalized for COPD between 2007 and 2015 were identified in a $1 / 97^{\text {th }}$ random sample of French claims data. Patients receiving dual therapy within 60 days after hospitalization were compared to patients receiving triple therapy, after propensity score matching on disease severity.

Results: Of the 3,089 patients hospitalized for COPD, 1,538 (49.8\%) received either dual or triple therapy in the 2 months following inclusion, and 1,500 (48.6\%) had at least 30 days of follow-up available; $846(27.4 \%)$ received dual therapy, and $654(21.2 \%)$ received triple therapy. After matching, the number of exacerbations was 2.4 per year in the dual vs 2.3 in the triple group $(p=0.45)$. Among newly treated patients $(\mathrm{n}=206)$, persistence at 12 months was similar in the dual and triple groups ( $48 \%$ vs $41 \%$, respectively, $p=0.37$ ). As compared to patients on dual therapy, more patients on triple therapy received oral corticosteroids $(49.1$ vs $40.4 \%, p=0.003)$ or were hospitalized for any reason $(67 \%$ vs $55.8 \%, p=0.0001)$ or for COPD (35.3 vs $25.1 \%, p=0.0002)$ during follow-up. Cost of care was higher for patients on triple than for those on dual therapy ( $€ 11,877.1$ vs $€ 9,825.1, p=0.01)$.

Conclusion: Following hospitalizations for COPD, patients on dual and triple therapy experienced recurrent exacerbations, limited adherence to therapies and high cost of care. Patients on triple therapy appeared more severe than those on dual therapy, as reflected by exacerbations and health care resource use.

Keywords: COPD, therapy, persistence, exacerbations, health care resource use

\section{Introduction}

COPD is characterized by chronic respiratory symptoms and persistent airflow limitation, due to cigarette smoking in the vast majority of cases. ${ }^{1-3}$ In patients aged 40 years or more, the prevalence of spirometry-confirmed COPD has been estimated at $7.5 \%$ in France in 2008, and between $4 \%$ and $26 \%$ in Europe. ${ }^{4,5}$ Epidemiological studies report a gradual increase in prevalence and related mortality in most countries. ${ }^{1}$ In 2013, between 95,000 and 145,000 COPD-related hospitalizations were recorded in France. ${ }^{6}$ The mortality associated with COPD is stable despite progress in care, which may relate to under- or late diagnoses of the disease. $^{6}$

Exacerbations prevention, dyspnea relief and health status improvement are the main attainable goals of care for COPD. Maintenance pharmacological therapy to 
prevent exacerbations relies on bronchodilators, with greater effects of long-acting anti-muscarinic agents (LAMAs) than long-acting beta-2 agonists (LABA), inhaled corticosteroids (ICS), phosphodiesterase-4 inhibitors (roflumilast, where available) and azithromycin. Guidelines propose recommendations on how to hierarchize these options, which are regularly evolving with the release of new products and evidence.

Fixed-dose combinations of triple therapy (LABA +LAMA+ICS) are available in France since 2018, but open triple associations can be used since 2005, when tiotropium was released and began being prescribed in association with ICS/LABA combinations. Analyzing real-life data on outcomes of patients receiving open triple combinations could help anticipate the potential interest of fixed triple combinations to prescribers and patients.

The objective of this study, based on a random sample of the French population affected by COPD, was to compare, after hospitalizations for COPD, the persistence and the effects of dual and triple therapies on exacerbations, health care resource use (HRU), and costs of care.

\section{Methods}

\section{Study design and data source}

The study was conducted on the General Sample of Beneficiaries (EGB) database, which is a random representative sample $\left(1 / 97^{\text {th }}\right)$ of the population covered by the French health care insurance system.

EGB records individual anonymous information from primary and secondary care (data from PMSI, the French Diagnosis Related Group-based medical information system), and it currently covers more than $90 \%$ of the French population. ${ }^{7,8}$ The EGB database contains general characteristics (gender, year of birth, month and year of death when applicable, free-access-to-care status [people whose financial resources are below a set threshold have their health care expenses $100 \%$ covered by the national public health insurance \{social security\}], residence area, longterm disease [LTD] status [patients registered for LTD benefit from full coverage for all medical expenses]), all non-hospital reimbursed health care expenditures with date and code (visits and medical procedures, lab tests, drugs and medical devices, but not the corresponding medical indication nor result), and hospital discharge summaries (ICD-10 diagnoses codes for all medical, obstetric, and surgery hospitalizations with the date and duration of hospitalization, medical procedures, hospitalization department and cost coding system).

\section{Selection criteria}

The study population comprised patients who were hospitalized with a primary or related diagnosis of COPD (ICD10 codes: J41, J42, J44, or J96.1 and J96.0 only when J43 or J44 in associated diagnoses) between January 2007 and February 2015, and who were aged 45 and over at the date of hospitalization.

Inclusion date was the date of discharge from the first hospitalization - meeting the inclusion criteria - recorded during the study period. Two sub-cohorts were constituted based on treatments dispensed during the 60-day period following the inclusion date: 1) a sub-cohort of patients treated with fixed or open dual therapy (LABA+LAMA or $\mathrm{LABA}+\mathrm{ICS}$ ) and 2) a sub-cohort of patients treated with open triple therapy (LABA+LAMA+ICS, fixed combination of which were not available during the study period) (Figure 1).

Index date was defined as the date of the last dispensing within the 60-day period following the inclusion date.

There was no exclusion criterion.

Patients were studied from their index date to the end of follow-up, ie, to the occurrence of one of the following events, whichever came first: treatment discontinuation, last patient's health record, patient's death or end of the study period.

\section{Outcomes}

\section{Exacerbations}

Exacerbations were identified through HRU as requirement of antibiotics, oral corticosteroids, hospitalization or any combination of these criteria. ${ }^{9-11}$ They were classified into moderate exacerbations requiring treatment with OCS and/or antibiotics, and severe exacerbations requiring hospitalizations. ${ }^{11}$ The number and nature of exacerbations were evaluated over the follow-up period.

\section{COPD-related HRU and associated costs}

HRU and associated costs were evaluated over the followup period. They included all COPD-related resource use for therapy (once-daily LABA/LAMA FDC, ICS/LABA FDC, ICS, SABA, LAMA, once-daily LABA, SABA/ SAMA FDC, LABA, SAMA, xanthines, antileukotrienes, injectable corticosteroids, oral corticosteroids, antibiotics, influenza and pneumococcal vaccines), medical acts 


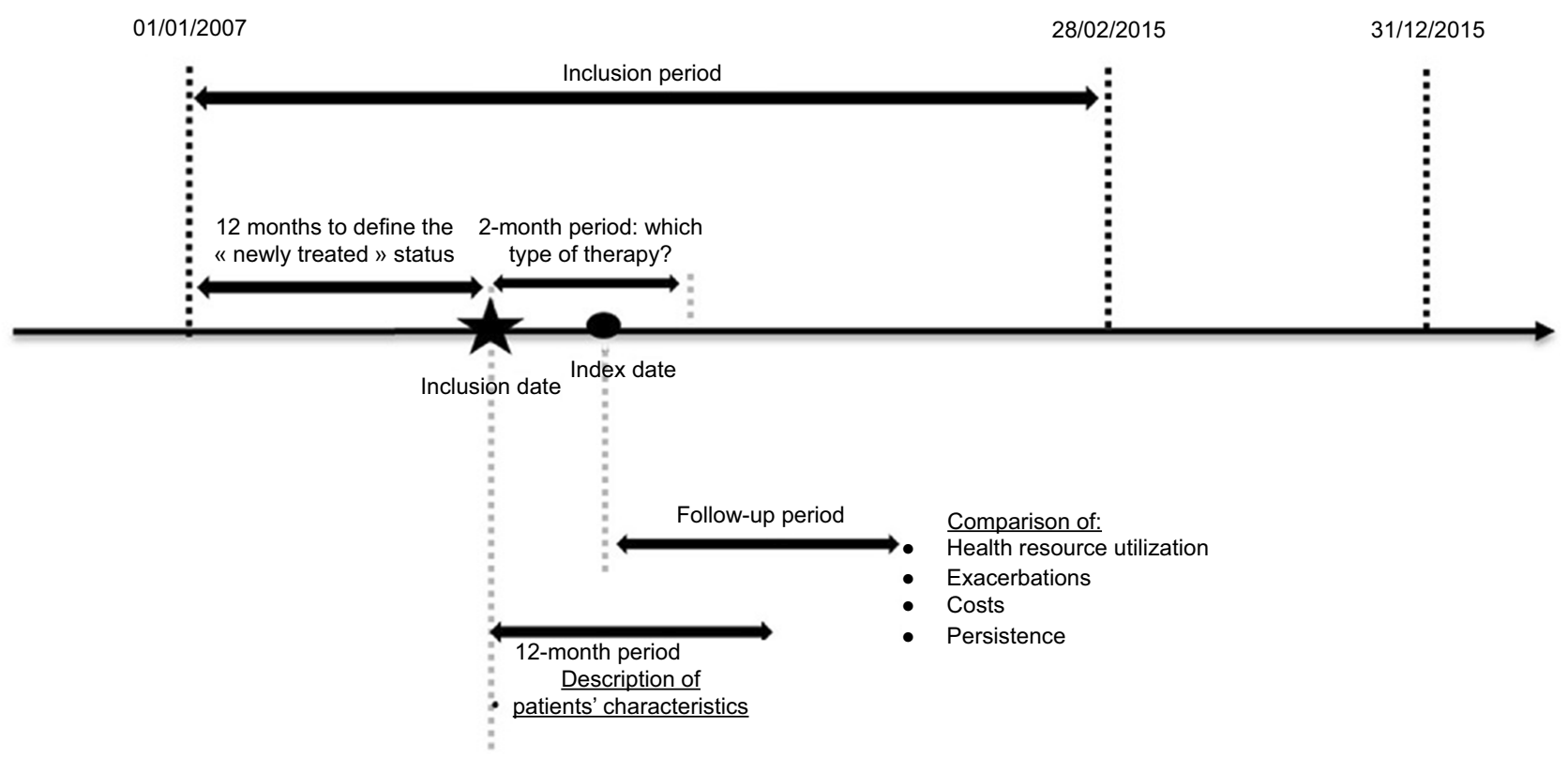

Figure I Study design.

(oxygen therapy, non-invasive ventilation, aerosol devices, pulmonary function testing, arterial blood gas measurement, chest X-rays and CT scans, continuous positive airway pressure and pulmonary rehabilitation), visits to general practitioners, respiratory physicians (private or hospital practitioners), and physiotherapists, hospitalizations for COPD, and all-cause hospitalizations.

\section{Treatment persistence}

Persistence to a given therapy is defined as the duration of time from initiation to discontinuation of this therapy. ${ }^{12,13}$ Therefore, persistence was studied only in newly treated patients, ie, without any dispensing of ICS, LABA or LAMA in the 12 months before inclusion date. A patient was considered as persistent if, during the 15-month follow-up period following the index date, no discontinuation exceeding 90 consecutive days was observed between the end of the coverage period of a dispensing and the subsequent treatment dispensing. This definition was based on the length of the coverage period for each treatment unit and the number of units: as one unit is usually prescribed for 30 days, 90 days correspond to three times the usual duration of treatment use.

To confirm the validity of our definition of persistence, a sensitivity analysis was performed, where non-persistence was defined as a treatment discontinuation of at least 61 instead of 91 consecutive days.

\section{Regulatory procedures}

This observational study was conducted on anonymized data and the National Informatics and Liberty Committee has delivered an overall authorization to use EGB data for research purposes to the PELyon team. This study was performed after approval by the French Institute for Health Data (Institut des Données de Santé), approval $\mathrm{n}^{\circ} 209$, September 21, 2016, and was submitted to The European Union electronic Register of PostAuthorization Studies (EU PAS Register number: EUPAS26916).

\section{Statistical analysis}

Sociodemographic factors (age, gender, free access to care status), mortality, LTD status for asthma or COPD and comorbidities (identified by LTD status or hospitalization diagnosis and/or three dispensing of specific treatments at three different quarters) were examined in the overall cohort and in treatment subgroups over the 12-month period after inclusion date, using descriptive statistics. Means and SD were used for continuous variables, and frequencies and percentages were used for categorical variables.

\section{Matching}

To obtain comparable groups, patients were matched (1:1) based on inclusion year, time between inclusion and index 
dates ( \pm 5 days), presence or not at the time of the combination of dual or triple therapies, and propensity scores.

Propensity score was calculated using a logistic regression model estimating the probability to be treated with a triple therapy, using the following confounding factors assessed during the 12 months before index date: age at inclusion date, gender, free access to care status, number of COPD maintenance treatments, number of exacerbations, number of visits to a general practitioner and to a respiratory physician, presence of comorbidities (cardiovascular diseases, depression, cancer and diabetes), use of oxygen therapy and non-invasive ventilation.

To study the impact of therapy on exacerbation rates, the annualized numbers of moderate and severe exacerbations were compared between dual and triple therapy during the follow-up period using a Wilcoxon test for matched data.

The number of users, as well as the annualized numbers of acts of care (treatments, visits, medical procedures, lab tests and hospitalizations) per user were described in both treatment subgroups during the follow-up period (in person-years). To study the potential impact of therapy on HRU and associated costs, percentages of users were compared between dual and triple therapy patients with the McNemar test; the annualized numbers of units delivered were compared with the Wilcoxon test for matched data.

The annualized costs related to the health care resource utilization during the follow-up period and the costs per major expenditure item were compared with the Wilcoxon test for matched data.

The 12-month persistence to COPD therapies was described for newly treated patients with 15 months of data available after the index date in both matched treatment sub-cohorts. The Kaplan-Meier method was used for description. The persistence was compared between subcohorts using a Cox model with a robust variance-covariance matrix to account for matched data.

\section{Results}

\section{Study population}

Of 4,407 patients with $\geq 1$ hospitalization for COPD between January 2007 and February 2015, 3,089 patients were aged 45 and over. Of these, 1,538 (49.8\%) received dual or triple therapy in the 2 months following inclusion, and 1,500 (48.6\%) had at least 30 days of follow-up available. For these 1,500 patients, the last dispensing in the 60-day period following inclusion date was a dual therapy for 846 patients $(56.4 \%)$, and a triple therapy for 654 patients (43.6\%) (Figure 2).

The 1:1 matching between dual and triple therapy resulted in 530 patients matched, ie, $81.0 \%$ of the patients under triple therapy.

In the matched dual and triple therapy cohorts, 103 pairs were evaluable for persistence, corresponding to those patients naive of maintenance therapy (ie, without dispensing of COPD medications in the 12 months prior to inclusion date) and with at least 15 months of data available after index date) (Figure 2).

Patient's characteristics are described in Table 1. Of the 3,089 patients hospitalized for COPD between 2007 and 2015 and aged over 45, 56.6\% were male and the mean age was 71.0 years at baseline. Among this population, 28.5\% had a LTD status for COPD and 5.0\% had a LTD for asthma. In the 12 months following hospital discharge, $780(25 \%)$ of patients did not receive any dispensing of LABA, LAMA or ICS. The other patients received different combinations of treatments: $366(11.8 \%)$ patients had only one therapeutic class, $926(30.0 \%)$ patients received two therapeutic classes and 1,017 (32.9\%) patients received the three therapeutic classes (Table 2).

\section{Distribution of patients by type of COPD medications at index date}

In the 846 patients who received dual therapy, 714 combinations of treatments $(84.4 \%)$ included LABA and ICS in FDCs or in free combinations, while $28(3.3 \%)$ were free combinations of LAMA and ICS, and 104 (12.3\%) free or fixed combinations of LABA/LAMA.

In triple therapy regimens, $654(100 \%)$ combinations of treatments included LABA and ICS in FDCs or in free combinations; of them $582(89.0 \%)$ included a FDC of LABA and ICS, while $72(11.0 \%)$ were free combinations of the three therapeutic classes (ICS+LABA+LAMA) without FDC (Table 3).

Characteristics of non-matched and matched patients on dual or triple therapies have been detailed in Table S1.

\section{Exacerbations}

All exacerbations combined, 381 matched patients $(71.9 \%)$ on dual therapy versus 404 matched patients $(76.2 \%)$ on triple therapy had at least one exacerbation during their follow-up. The mean number of exacerbations per year did not differ between groups (2.4 vs 2.3, $p=0.4464)$. The trends were similar for moderate and 


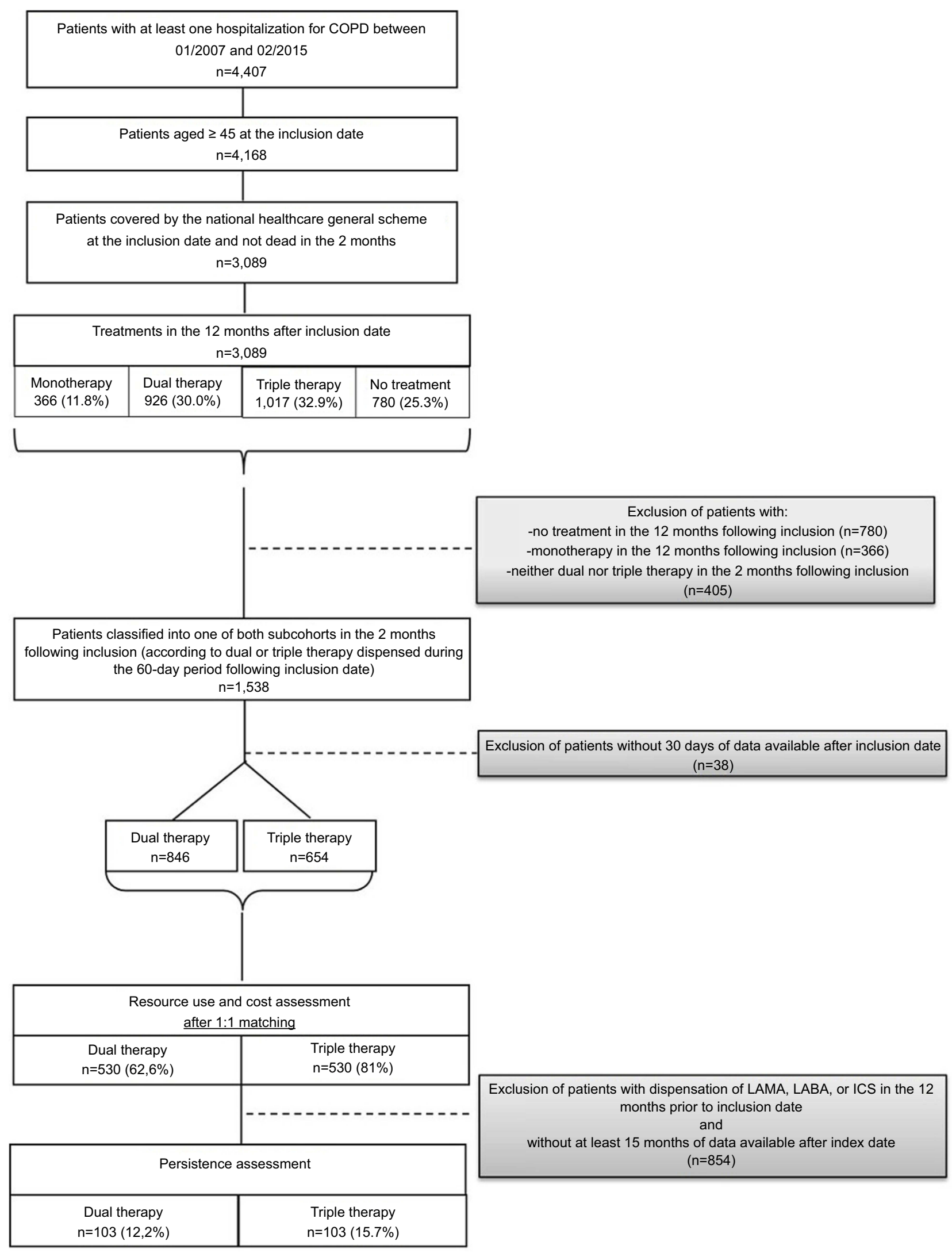

Figure 2 Flow chart.

Abbreviations: ICS, inhaled corticosteroid; LABA, long-acting beta-agonist; LAMA, longacting muscarinic antagonist. 
Table I Patients' characteristics $(n=3,089)$

\begin{tabular}{|c|c|c|c|}
\hline & $\begin{array}{l}\text { Overall cohort } \\
(n=3,089)\end{array}$ & $\begin{array}{l}\text { Dual therapy } \\
(n=846)\end{array}$ & $\begin{array}{l}\text { Triple therapy } \\
(\mathrm{n}=654)\end{array}$ \\
\hline Mean age at inclusion date $( \pm S t D)$ & $71.0(12.3)$ & $71.1(12.2)$ & $68.3(10.9)$ \\
\hline \multicolumn{4}{|l|}{ Age class (in the year following inclusion) (\%) } \\
\hline $45-54$ & 11.5 & II.I & 11.4 \\
\hline $55-64$ & 20.6 & 19.8 & 25.8 \\
\hline $65-74$ & 24.4 & 24.7 & 30.3 \\
\hline $75-79$ & 14.6 & 30.8 & 26.0 \\
\hline$>80$ & 28.9 & 13.5 & 6.5 \\
\hline Men (\%) & 56.6 & 53.0 & 67.0 \\
\hline \multicolumn{4}{|l|}{$\begin{array}{l}\text { LTD status for chronic severe respiratory failure (in the year fol- } \\
\text { lowing inclusion) (\%) }\end{array}$} \\
\hline COPD & 28.5 & 32.9 & 47.6 \\
\hline Asthma & 5.0 & 9.3 & 7.2 \\
\hline $\begin{array}{l}\text { Hospitalization with diagnosis of asthma in the year following } \\
\text { inclusion (\%) }\end{array}$ & 1.3 & 2.7 & 1.1 \\
\hline \multicolumn{4}{|l|}{ Comorbidities (in the year following inclusion) (\%) } \\
\hline Cardiovascular diseases & 73.9 & 77.5 & 72.0 \\
\hline Depression & 23.8 & 23.2 & 20.5 \\
\hline Cancers & 18.8 & 16.9 & 18.5 \\
\hline Diabetes (type I and type 2) & 21.0 & 22.9 & 17.6 \\
\hline Dead (in the year following inclusion) (\%) & 12.7 & 10.1 & 9.2 \\
\hline
\end{tabular}

Abbreviation: LTD status, long-term disease status.

severe exacerbations, but all were non-significant: the proportion of patients with severe exacerbations was lower in patients receiving dual therapy (25.1\%) than in patients receiving triple therapy (35.5\%), but among exacerbators, the mean number of severe exacerbations was lower in patients under triple therapy (1.8, SD: 2.4) than in patients under dual therapy (2.2, SD: 2.4). Similarly, the proportion of patients with moderate exacerbations was slightly lower in patients receiving dual therapy $(61.1 \%)$ than in patients receiving triple therapy (66.8\%), but again, among exacerbators, the mean number of moderate exacerbations was lower in patients under triple therapy (2.4, SD: 2.4) than in patients under dual therapy (3.1, SD: 2.8) (Table 4).

\section{Health care resource use}

Compared to patients receiving dual therapy, those on triple therapy were more likely to visit physiotherapists $(23.6 \%$ vs $18.9 \%, p=0.05)$ and hospital practitioners ( $50.2 \%$ vs $41.1 \%, p=0.002$ ), to receive oral corticosteroids ( $49.1 \%$ vs $40.4 \%, p=0.003)$, or influenza vaccines $(50.0 \%$ vs $41.5 \%, p=0.01$ ), to have Pulmonary Function Testing during outpatient visits (PFT: $59.8 \%$ vs $44.7 \%, p<0.0001$ ), to have X-rays and chest CT scans $(50.0 \%$ vs $36.6 \%$, $p<0.0001$ ), or non-invasive ventilation during hospitalization $(12.1 \%$ vs $7.4 \%, p=0.01)$, and to be hospitalized for any reason $(67.0 \%$ vs $55.8 \%, p=0.0001)$, or for COPD (35.3\% vs $25.1 \%, p=0.0002$ ) (Table 5 ).

On average, over 1 year, matched patients under dual therapy received less antibiotics than those under triple therapy $(62.8 \%$ vs $68.3 \%, p=0.05)$.

\section{Costs}

On average, during the follow-up period, matched patients receiving triple therapy had a higher total annual cost than those under dual therapy ( $€ 11,877$ vs $€ 9,825, p=0.01$ ), mainly due to higher hospitalization ( $€ 9,097$ vs $€ 7,240$ ), and more marginally to drug costs ( $€ 982$ vs $€ 728$ ) (Table 6).

\section{Persistence}

Among matched newly treated subgroups, more patients had a LTD status for COPD in the triple than in the dual therapy subgroup ( $30 \%$ vs $20 \%, p=0.11$ ). Among these 
Table 2 Treatment combinations observed in the 12 months following inclusion date in the study population $(n=3,089)$

\begin{tabular}{|l|l|l|}
\hline Treatments & $\mathbf{N}$ & $\%$ \\
\hline No dispensing of LABA, LAMA or ICS & $\mathbf{7 8 0}$ & $\mathbf{2 5 . 3 \%}$ \\
\hline Monotherapy & $\mathbf{3 6 6}$ & $\mathbf{1 1 . 8 \%}$ \\
ICS & 181 & $5.9 \%$ \\
LABA & 65 & $2.1 \%$ \\
LAMA & 120 & $3.9 \%$ \\
\hline Dual therapy & $\mathbf{9 2 6}$ & $\mathbf{3 0 . 0 \%}$ \\
LABA/ICS FDC & 462 & $15.0 \%$ \\
LABA/ICS FDC+ICS & 151 & $4.9 \%$ \\
LABA/ICS FDC+ICS+LABA & 35 & $1.1 \%$ \\
LABA/ICS FDC+LABA & 51 & $1.7 \%$ \\
LABA/LAMA FDC & 1 & $0.03 \%$ \\
LABA/LAMA FDC+LABA+LAMA & 3 & $0.1 \%$ \\
LABA/LAMA FDC+LAMA & 1 & $0.03 \%$ \\
ICS+LABA & 92 & $3.0 \%$ \\
ICS+LAMA & 47 & $1.5 \%$ \\
LABA+LAMA & 83 & $2.7 \%$ \\
\hline Triple therapy & $\mathbf{1}, 017$ & $\mathbf{3 2 . 9 \%}$ \\
LABA/ICS FDC+LABA/LAMA FDC & 4 & $0.1 \%$ \\
LABA/ICS FDC+LABA/LAMA FDC+ICS+LABA & 1 & $0.03 \%$ \\
+LAMA & & \\
LABA/ICS FDC+LABA/LAMA FDC+ICS+LAMA & 7 & $0.2 \%$ \\
LABA/ICS FDC+LABA/LAMA FDC+LABA & 4 & $0.1 \%$ \\
+LAMA & & \\
LABA/ICS FDC+LABA/LAMA FDC+LAMA & 4 & $0.1 \%$ \\
LABA/ICS FDC+ICS+LABA+LAMA & 70 & $2.3 \%$ \\
LABA/ICS FDC+ICS+LAMA & 178 & $5.8 \%$ \\
LABA/ICS FDC+LABA+LAMA & 94 & $3.0 \%$ \\
LABA/ICS FDC+LAMA & 543 & $17.6 \%$ \\
LABA/LAMA FDC+ICS & 1 & $0.03 \%$ \\
LABA/LAMA FDC+ICS+LABA & $0.03 \%$ \\
LABA/LAMA FDC+ICS+LABA+LAMA & $0.03 \%$ \\
ICS+LABA+LAMA & $3.5 \%$ \\
\hline
\end{tabular}

Note: Bold texts and values represent main subgroups.

Abbreviations: LABA, long-acting beta-agonist; LAMA, long-acting muscarinic antagonist; ICS, inhaled corticosteroid; FDC, fixed-dose combination.

matched initiators, $73 \%$ of those on dual therapy initiated a LABA/ICS FDC, the others initiated a free combination. Among those on triple therapy, 91\% initiated a LABA/ICS FDC+ a LAMA, the others initiated a free combination.

One year after initiation of treatment, patients on triple therapy were more likely to have stopped at least one treatment than those on dual therapy $(59.2 \%$ of non-persistent patients vs $52.2 \%$, Kaplan-Meier method) (Figure $3)$. Persistence rate was low in both groups according to both definitions of non-persistence. The Cox model used
Table 3 Distribution of type of COPD medications by subcohort at index date $(n=I, 500)$

\begin{tabular}{|l|l|l|}
\hline Treatments & $\mathbf{N}$ & $\%$ \\
\hline Dual therapy & $\mathbf{8 4 6}$ & $\mathbf{5 6 . 4 \%}$ \\
FDC LABA/ICS & 525 & $35.0 \%$ \\
LABA+LAMA & 103 & $6.9 \%$ \\
ICS+LABA & 86 & $5.7 \%$ \\
FDC LABA/ICS+ICS & 62 & $4.1 \%$ \\
FDC LABA/ICS+LABA & 32 & $2.1 \%$ \\
ICS+LAMA & 28 & $1.9 \%$ \\
FDC LABA/ICS+ICS+LABA & 9 & $0.6 \%$ \\
FDC LABA/LAMA & 1 & $0.1 \%$ \\
\hline Triple therapy & $\mathbf{6 5 4}$ & $\mathbf{4 3 . 6 \%}$ \\
FDC LABA/ICS+LAMA & 485 & $32.3 \%$ \\
ICS+LABA+LAMA & 72 & $4.8 \%$ \\
FDC LABA/ICS+ICS+LAMA & $6 I$ & $4.1 \%$ \\
FDC LABA/ICS+LABA+LAMA & 26 & $1.7 \%$ \\
FDC LABA/ICS+ICS+LABA+LAMA & 7 & $0.5 \%$ \\
FDC LABA/ICS+FDC LABA/LAMA & $\mathrm{I}$ & $0.1 \%$ \\
FDC LABA/ICS+FDC LABA/LAMA+ICS+LAMA & $\mathrm{I}$ & $0.1 \%$ \\
FDC LABA/ICS+FDC LABA/LAMA+LAMA & $\mathrm{I}$ & $0.1 \%$ \\
\hline
\end{tabular}

Note: Bold texts and values represent main subgroups.

Abbreviations: LABA, long-acting beta-agonist; LAMA, long-acting muscarinic antagonist; ICS, inhaled corticosteroid; FDC, fixed-dose combination.

to compare persistence at 12 months between patients receiving dual therapy vs triple therapy did not show a significant difference between groups (HR $\left[\begin{array}{ll}95 \% & \mathrm{CI}\end{array}\right]$ $=0.851[0.601,1.206] ; p=0.3655)$.

Results of sensitivity analysis, where non-persistence was defined as a treatment discontinuation of at least 61 instead of 91 consecutive days, have been detailed in Table S2.

\section{Discussion}

\section{Main findings}

Among 3,089 patients hospitalized for COPD and aged $\geq 45$, the last dispensing in the 2 months following inclusion was a dual therapy for $846(27.4 \%)$, and a triple therapy for $654(21.2 \%)$.

After matching dual and triple therapy patients, the mean annualized number of moderate and severe exacerbations over the follow-up period was high and did not differ between both groups (2.4 vs 2.3 , NS). Overall, patients with triple therapy had higher COPD-related HRU and costs than patients with dual therapy, mainly due to hospitalizations, and to a lesser extent to drug costs. There was also a low persistence to both dual and triple therapies: of the 103 matched patients in each group, $47.8 \%$ were persistent to dual therapy compared to $40.8 \%$ of patients on triple therapy (NS). 
Table 4 Distribution and comparison of the number of exacerbations between matched patients under dual therapy and those under triple therapy, over the follow-up period, using Wilcoxon test

\begin{tabular}{|c|c|c|c|c|c|}
\hline \multirow[t]{2}{*}{ Exacerbations } & \multicolumn{2}{|c|}{ Dual therapy $(\mathrm{N}=530)$} & \multicolumn{2}{|c|}{ Triple therapy $(\mathrm{N}=530)$} & \multirow{2}{*}{$\frac{p \text {-value }}{\text { Overall }^{\mathrm{b}}}$} \\
\hline & Exacerbators $^{\mathbf{a}}$ & Overall $^{\mathbf{b}}$ & Exacerbators $^{\mathbf{a}}$ & Overall $^{\mathbf{b}}$ & \\
\hline \multicolumn{6}{|c|}{ All exacerbations combined } \\
\hline$N(\%)$ & 381 (100.0\%) & 381 (7I.9\%) & $404(100.0 \%)$ & 404 (76.2\%) & \\
\hline Mean (StD) & $3.4(2.8)$ & $2.4(2.8)$ & $3.0(2.6)$ & $2.3(2.6)$ & 0.4464 \\
\hline Median (IQR) & $2.7(1.3-4.8)$ & $1.6(0-3.9)$ & $2.3(1.2-3.9)$ & $1.6(0.2-3.3)$ & \\
\hline Min-Max & $0.1-14.1$ & $0.0-14.1$ & $0.1-12.2$ & $0.0-12.2$ & \\
\hline \multicolumn{6}{|l|}{ Moderate $^{c}$} \\
\hline$N(\%)$ & $324(100.0 \%)$ & $324(6 \mid .1 \%)$ & 354 (100.0\%) & $354(66.8 \%)$ & \\
\hline Mean (StD) & $3.1(2.8)$ & $1.9(2.6)$ & $2.4(2.4)$ & $1.6(2.3)$ & 0.2037 \\
\hline Median (IQR) & $2.2(1.1-4.2)$ & $0.8(0.0-2.8)$ & I.8 $(0.9-3.3)$ & $0.9(0.0-2.4)$ & \\
\hline Min-Max & $0.1-14.1$ & $0.0-14.1$ & $0.1-12.2$ & $0.0-12.2$ & \\
\hline \multicolumn{6}{|l|}{ Severe $^{d}$} \\
\hline$N(\%)$ & $133(100.0 \%)$ & $133(25.1 \%)$ & $188(100.0 \%)$ & 188 (35.5\%) & \\
\hline Mean $(\mathrm{StD})$ & $2.2(2.4)$ & $0.6(1.6)$ & I.8 (2.4) & $0.7(1.7)$ & 0.1163 \\
\hline Median (IQR) & $1.2(0.7-3)$ & $0.0(0-0.2)$ & $1.0(0.5-1.9)$ & $0.0(0.0-0.5)$ & \\
\hline Min-Max & $0.2-12.2$ & $0.0-12.2$ & $0.1-12.2$ & $0.0-12.2$ & \\
\hline
\end{tabular}

Notes: "Exacerbators" corresponded to patients with at least one exacerbation over their follow-up period; "'Overall" corresponded to the overall studied population with or without exacerbation; ' moderate exacerbations were defined by any dispensing of treatment with OCS and/or antibiotics; ${ }^{d}$ severe exacerbations corresponded to hospitalizations.

\section{Internal and external validity}

These patients hospitalized for COPD represented $0.47 \%$ of the whole French population covered by the national health care system, and $1.05 \%$ of the population aged $45+$. This percentage is to be compared to the figures mentioned in a recent report on COPD in France, ie, $10-15 \%$ of COPD patients have a III and IV GOLD stage (corresponding to 175,000 patients, or $0.3 \%$ of the full population). ${ }^{14}$

A major advantage of our study was the ability to describe COPD care, from national population-based data. As the French health care system is universal, the data are representative of the whole population. Therefore, our results may be extrapolated to the whole French COPD population of mild to high severity experiencing a severe exacerbation (ie, hospitalization).

In the year following hospital discharge, $25 \%$ of patients did not receive any dispensing of LABA, LAMA or ICS. The other patients received different combinations of treatments: $366(11.8 \%)$ patients had only one of three therapeutic classes, $926(30.0 \%)$ patients received two therapeutic classes and 1017 (32.9\%) patients received the three therapeutic classes. These figures provide a picture of current care for COPD in France following hospitalization.
In Germany, Mueller et al studied patients aged $\geq 40$ with at least one hospitalization or two outpatients visits for COPD in 2010-2011, and at least a prescription of LABA, LAMA, ICS or/and ICS/LABA FDC during the follow-up. Inclusion criteria were close to ours, as were their patients' characteristics: mean age of 71.4 years, $45.2 \%$ of women. ${ }^{15}$ Of patients who received at least one prescription of a long-acting medication, $33.6 \%$ received at least one prescription of a LABA, $49.8 \%$ of a LAMA, $18.5 \%$ of an ICS and $46.3 \%$ of ICS/LABA-fixed dose combination.

In our study, $87.7 \%$ of dual and $100 \%$ of triple therapy patients received ICS. As a result of these high figures, no conclusion could be drawn regarding a potential, specific impact of ICS in COPD. In France, ICS are commonly prescribed in COPD, regardless of severity, and despite recommendations for a more limited use. ${ }^{11,16-18}$

For all COPD therapies, our study showed low persistence rates $(47.8 \%$ of persistence to dual therapy compared to $40.8 \%$ to triple therapy [NS]). Our definition of persistence (non-interruption of treatment for 90 consecutive days in the 12 months period following initiation) has been commonly used for COPD. ${ }^{13,19-21}$ To confirm the validity of our approach, a sensitivity analysis was performed using a treatment discontinuation of 61 instead 
Table 5 Health care resource use in patients receiving dual therapy versus triple therapy

\begin{tabular}{|c|c|c|c|c|c|c|}
\hline \multirow{2}{*}{$\begin{array}{l}\text { Health care resource } \\
\text { use }\end{array}$} & \multicolumn{2}{|c|}{ Dual therapy $(n=530)$} & \multicolumn{2}{|c|}{ Triple therapy $(n=530)$} & \multirow{2}{*}{$\begin{array}{l}\text { Comparison } \\
\text { number of } \\
\text { patients } \\
\text { p-value* }\end{array}$} & \multirow{2}{*}{$\begin{array}{l}\text { Comparison } \\
\text { number of care } \\
\text { p-value** }\end{array}$} \\
\hline & $\begin{array}{l}\text { Number of } \\
\text { patients (\%) }\end{array}$ & $\begin{array}{l}\text { Mean number } \\
\text { of care (Std) }\end{array}$ & $\begin{array}{l}\text { Number of } \\
\text { patients (\%) }\end{array}$ & $\begin{array}{l}\text { Mean number } \\
\text { of care (Std) }\end{array}$ & & \\
\hline $\begin{array}{l}\text { Consultations } \\
\text { General practitioners } \\
\text { Lung specialists } \\
\text { Physiotherapists } \\
\text { Hospital practitioners } \\
\text { (all specialties } \\
\text { combined) }\end{array}$ & $\begin{array}{l}480(90.6 \%) \\
72(13.6 \%) \\
100(18.9 \%) \\
218(41.1 \%)\end{array}$ & $\begin{array}{l}\text { II.I (I0.2) } \\
0.4(1.8) \\
9.8(32.5) \\
1.6(3.4)\end{array}$ & $\begin{array}{l}477(90.0 \%) \\
89(16.8 \%) \\
125(23.6 \%) \\
266(50.2 \%)\end{array}$ & $\begin{array}{l}10.0(9.4) \\
0.6(3.1) \\
8.8(27.6) \\
1.7(3.5)\end{array}$ & $\begin{array}{l}0.7477 \\
0.1284 \\
0.0474 \\
0.0018\end{array}$ & $\begin{array}{l}0.1003 \\
0.7901 \\
0.9177 \\
0.2540\end{array}$ \\
\hline $\begin{array}{l}\text { Treatments } \\
\text { LABA } \\
\text { Once-daily LABA } \\
\text { ICS } \\
\text { LAMA } \\
\text { LABA/ICS FDC } \\
\text { LABA/LAMA FDC } \\
\text { SABA } \\
\text { SABA/SAMA FDC } \\
\text { SAMA } \\
\text { Xanthines } \\
\text { Antileukotrienes } \\
\text { Oral corticosteroids } \\
\text { Injectable } \\
\text { corticosteroids } \\
\text { Respiratory antibiotics } \\
\text { Influenza vaccine } \\
\text { Pneumococcal vaccine }\end{array}$ & $\begin{array}{l}99(18.7 \%) \\
50(9.4 \%) \\
145(27.4 \%) \\
177(33.4 \%) \\
329(62.1 \%) \\
7(1.3 \%) \\
278(52.5 \%) \\
66(12.5 \%) \\
129(24.3 \%) \\
26(4.9 \%) \\
77(14.5 \%) \\
214(40.4 \%) \\
52(9.8 \%) \\
333(62.8 \%) \\
220(41.5 \%) \\
70(13.2 \%)\end{array}$ & $\begin{array}{l}1.8(5.1) \\
0.7(2.6) \\
2.2(6.0) \\
2.0(3.8) \\
5.3(5.8) \\
0.1(0.7) \\
5.0(8.4) \\
2.3(9.2) \\
6.6(19.6) \\
0.7(3.7) \\
1.0(3.1) \\
3.1(8.3) \\
0.9(6.1) \\
7.8(14.8) \\
0.5(1.3) \\
0.2(0.7)\end{array}$ & $\begin{array}{l}77(14.5 \%) \\
46(8.7 \%) \\
153(28.9 \%) \\
46 I(87.0 \%) \\
4 I I(77.5 \%) \\
12(2.3 \%) \\
300(56.6 \%) \\
49(9.2 \%) \\
132(24.9 \%) \\
38(7.2 \%) \\
71(13.4 \%) \\
260(49.1 \%) \\
52(9.8 \%) \\
362(68.3 \%) \\
265(50.0 \%) \\
9 \mid(I 7.2 \%)\end{array}$ & $\begin{array}{l}\text { I.2(4.0) } \\
0.4(1.6) \\
2.3(6.5) \\
6.9(5.1) \\
7.5(8.6) \\
0.1(1.0) \\
5.4(10.1) \\
1.2(6.5) \\
6.5(22.3) \\
0.9(4.8) \\
0.9(3.4) \\
2.8(6.6) \\
1.1(9.6) \\
7.7(14.1) \\
0.4(0.6) \\
0.1(0.6)\end{array}$ & $\begin{array}{l}0.0630 \\
0.6587 \\
0.5553 \\
<0.0001 \\
<0.0001 \\
0.2253 \\
0.1624 \\
0.0939 \\
0.8273 \\
0.1213 \\
0.5987 \\
0.0034 \\
1 \\
\\
0.0532 \\
0.0055 \\
0.0728\end{array}$ & $\begin{array}{l}0.0286 \\
0.0122 \\
0.9934 \\
<0.0001 \\
<0.0001 \\
0.1540 \\
0.9160 \\
0.0052 \\
0.3299 \\
0.5098 \\
0.2156 \\
0.2174 \\
0.9668 \\
0.9324 \\
0.6275 \\
0.7984\end{array}$ \\
\hline $\begin{array}{l}\text { Medical procedures } \\
\text { Pulmonary function test } \\
\text { (PFT) } \\
\text { Chest X-ray and CT-scan } \\
\text { Non-invasive ventilation } \\
\text { Oxygen therapy } \\
\text { Continuous positive air- } \\
\text { way pressure }\end{array}$ & $\begin{array}{l}30 \text { I }(56.8 \%) \\
303(57.2 \%) \\
8 \text { I ( } 15.3 \%) \\
120(22.6 \%) \\
29(5.5 \%)\end{array}$ & $\begin{array}{l}2.9(7.1) \\
3(6.6) \\
4.8(23.8) \\
8.6(22.5) \\
2(9.2)\end{array}$ & $\begin{array}{l}363(68.5 \%) \\
370(69.8 \%) \\
107(20.2 \%) \\
140(26.4 \%) \\
24(4.5 \%)\end{array}$ & $\begin{array}{l}2.9(4.5) \\
4(11.3) \\
4.4(16.3) \\
9.0(19.5) \\
1.6(9.1)\end{array}$ & $\begin{array}{l}<0.0001 \\
<0.0001 \\
0.0436 \\
0.1510 \\
0.4838\end{array}$ & $\begin{array}{l}0.0367 \\
0.2205 \\
0.6348 \\
0.6803 \\
0.4551\end{array}$ \\
\hline Nebulizers & $193(36.4 \%)$ & $3.4(7.1)$ & $215(40.6 \%)$ & $3.4(7.7)$ & 0.1451 & 0.6210 \\
\hline $\begin{array}{l}\text { Hospitalizations } \\
\text { Hospitalizations for all } \\
\text { causes } \\
\text { COPD-related } \\
\text { hospitalizations }\end{array}$ & $\begin{array}{l}296(55.8 \%) \\
133(25.1 \%)\end{array}$ & $\begin{array}{l}2.5(5.5) \\
0.6(1.7)\end{array}$ & $\begin{array}{l}355(67.0 \%) \\
187(35.3 \%)\end{array}$ & $\begin{array}{l}3.0(7.8) \\
0.8(2.0)\end{array}$ & $\begin{array}{l}0.0001 \\
0.0002\end{array}$ & $\begin{array}{l}0.0849 \\
0.0821\end{array}$ \\
\hline
\end{tabular}

Notes: *McNemar test. **Wilcoxon test for matched data.

Abbreviations: LABA, long-acting beta-agonist; LAMA, long-acting muscarinic antagonist; ICS, inhaled corticosteroid; FDC, fixed-dose combination; SABA, short-acting beta-agonist; SAMA, short-acting muscarinic antagonist.

of 91 consecutive days: with a cutoff at 61 days, patients were less persistent to the same therapeutic classes. Our persistence rates were consistent with those found in other persistence studies, although few were based on claims data. ${ }^{15,22-27}$ Claims databases are increasingly used as sources of adherence and persistence data because they include large populations over prolonged time periods, without recall bias. However, claims data 
Table 6 Comparison of total costs (in $€$ ) associated with health care resource use between matched patients under dual therapy and those under triple therapy, over the study period, using Wilcoxon test

\begin{tabular}{|l|l|l|l|}
\hline \multirow{2}{*}{ Costs } & Dual therapy $(\mathbf{n = 5 3 0 )}$ & Triple therapy $(\mathbf{n = 5 3 0 )}$ \\
\cline { 2 - 4 } & Mean cost (ET) & Mean cost (ET) & \multirow{2}{*}{} \\
\hline Drug costs & $727.8(673.8)$ & $981.5(822.7)$ & $0.000 \mathrm{I}$ \\
Costs not related to drugs & $1,856.9(3063.6)$ & $1,798.8(2267.6)$ & 0.8896 \\
Hospitalizations & $7,240.4(17,825.8)$ & $9,096.9(20,304.2)$ & 0.0086 \\
Total & $9,825.1(18,665.1)$ & $11,877.1(20,951.2)$ & 0.0087 \\
\hline
\end{tabular}

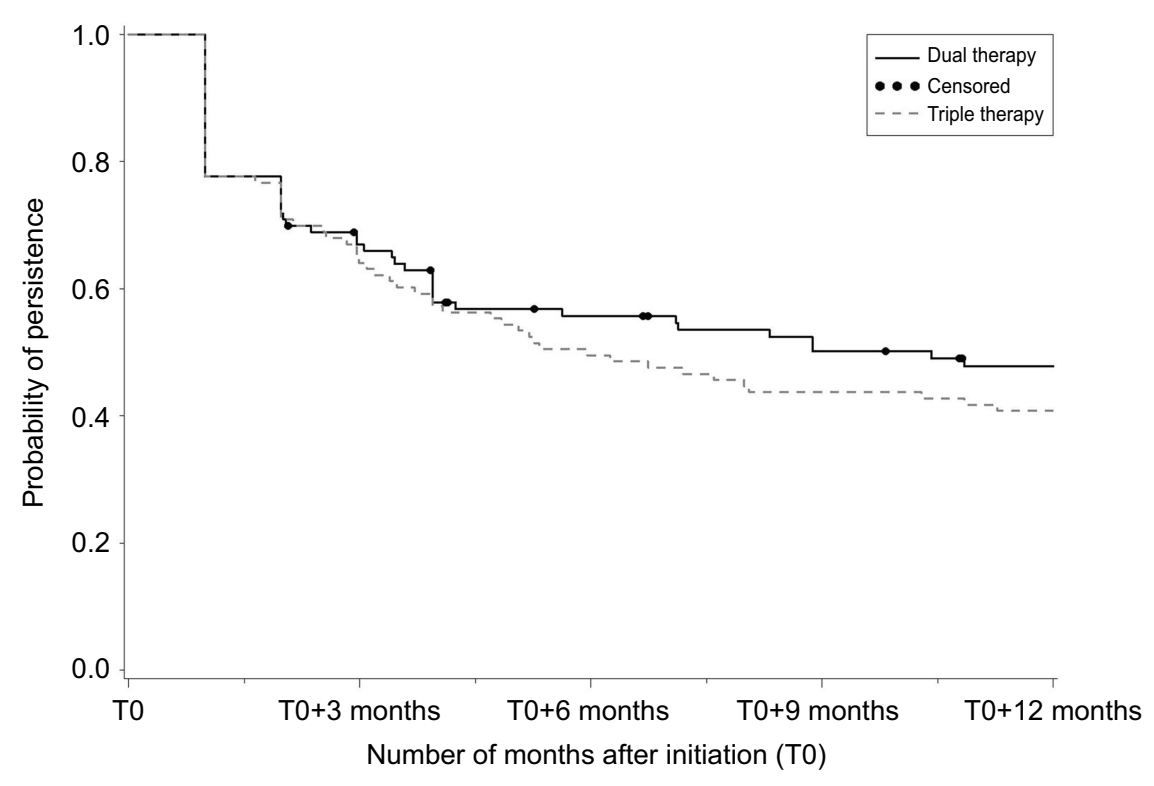

Figure 3 Description of persistence at 12 months after index date (T0), with Kaplan-Meier method ( $\mathrm{n}=206)$.

do not inform whether treatment discontinuation was decided by patients or by prescribers, neither the exact dates of cessation, nor the reasons of discontinuation.

The economic burden of COPD in France has been the subject of only few studies. ${ }^{28-30}$ Our findings on resource use and costs are consistent with the most recent one, conducted on EGB in 2011 that estimated an annual mean cost per patient of $€ 9,382$, with $€ 5,342$ directly related to COPD. ${ }^{30}$ Our findings are also comparable to several other recent studies in various countries. For instance, in a US study led by Pasquale et al in patients with COPD claims between 2007 and 2009, COPD-related mean annual costs were about $€ 5,600$ for patients with two or more exacerbations. ${ }^{31}$ Punekar et al studied the cost burden of COPD patients initiating LABA, LAMA or ICS/LABA between 2009 and 2013 and found that among adherent patients the total annual per patient cost of COPD varied between $€ 3,169$ and $€ 3,845$ according to the prescribed therapy. Their population was probably less severe as they were treatment initiators. ${ }^{32}$ Another recent US study estimated the COPD-related health care costs of COPD between $€ 5,800$ and $€ 6,800$ in moderately adherent to adherent patients. ${ }^{33}$ A study led in Canada from 2001 to 2010 showed hospitalizations and medications were primary drivers of COPD-related costs, as shown in our study. ${ }^{34}$

\section{Interpretation of results}

The low persistence could possibly be due to the age of our population: $16 \%$ of the matched initiators were aged 80 and over. Nevertheless, the possible association between age and persistence is controversial. While some studies have not identified a relationship between age and persistence, ${ }^{35}$ others have shown a higher persistence in older patients that are more frequently hospitalized (many comorbidities) and more closely followed. ${ }^{15,36,37}$ However, older patients also used more treatments (for instance treatments for cardiovascular diseases), and high number of concomitant treatments 
may affect the patients' persistence to some therapeutic classes. ${ }^{38}$ Our data also suggest that if triple therapy must be prescribed, their use would last longer under fixed than under free combinations. Inherent to our study design, nonpersistence was more likely in patients on triple than on dual therapy since no fixed triple therapy existed during the study period, while fixed dual options were available. This probably contributed to our results.

In our population, the addition of a third therapy was not associated with more favorable outcomes: after matching dual and triple therapy patients, the mean annualized number of exacerbations over the follow-up period did not differ between both groups (2.4 vs 2.3 , NS). Similar observations were reported in the DACCORD observational study, conducted in primary and secondary care in Germany. ${ }^{39}$ In this study, over 1 year, fewer patients with dual bronchodilation exacerbated than those receiving triple therapy $(15.5 \%$ vs $26.6 \%$; $p=0.001)$.

One explanation for these findings could be that patients prescribed triple therapy remain more severe than those receiving dual treatment even after careful matching, due to residual confounders. This may have occurred in our population, as $35.3 \%$ of matched patients in the triple therapy subgroup $(\mathrm{n}=530)$ were hospitalized for COPD during the follow-up period vs $25.1 \%$ of those in the dual therapy subgroup. Consumption of LAMA and FDC LABA/ICS was also more frequent in matched patients treated with triple therapy $(87.0 \%$ and $77.5 \%$, respectively, vs $33.4 \%$ and $62.1 \%$ in patients under dual therapy). Twenty-five percent of the matched patients had at least four exacerbations: the study showed more hospitalizations in patients under triple therapy.

Also, as day-to-day adherence ("implementation") was not measured in our study, we cannot exclude the possibility that the observed impacts of therapy could be explained by differences in adherence to separate inhalers compared with FDCs. In particular, since no single inhaler triple therapy was available at the inclusion time, patients in the triple therapy groups had to be using at least two inhalers. Poor adherence could, therefore, potentially impact these patients more than those in the dual therapy subgroup, that were mostly treated with FDCs.

\section{Limitations}

Some limitations should be acknowledged:

The EGB does not record diagnoses in primary care, it only contains hospital discharge summaries. Our selection algorithm was therefore specific but not sensitive, ie,
COPD patients without hospitalization were not captured. Nevertheless, the study population was identified from hospital discharge diagnoses, a valid criterion to identify COPD, used as a proxy in other studies. ${ }^{30,40}$

As is always the case with claims data, this study had no access to clinical, biological or lung function data, pivotal to assess severity. However, our inclusion criteria (following a hospitalization) and data on exacerbation and mortality rates, as well as the prevalence of comorbidities, suggested a moderate to severe level of severity in the population included.

Antileukotrienes were dispensed to about $14 \%$ of patients in both groups, which suggests that our population may have included some asthma patients. To verify whether contamination by asthma patients was more frequent in one of the groups, we looked for records of hospital admissions with main diagnosis of asthma in the year following inclusion: the results were comparable $(2.7 \%$ in the dual therapy group, vs $1.1 \%$ in the triple therapy group), supporting the absence of impact.

As is also the case when claims data are used, real use of medications remained unknown: only dispensing data were available, without information about the quality of use of inhaler devices, neither about actual use by patients. ${ }^{41}$ Nonpersistence could have been over- or underestimated. However, while many studies conducted in other countries used prescribing data, the claims data used in our study provided information on actual dispensing of therapy by community pharmacies, which is a major advantage as these data are closer to real consumption than prescribing data. Another limitation could come from the study duration: the therapeutic management of patients after hospitalization for COPD may have evolved over eight years.

Matching was performed to evaluate outcomes on therapy in patients as comparable as possible. This method however reduced the size of the study population, and hence the power of the comparisons. Moreover, persistence was studied in newly treated patients only, further reducing the number of patients in each subgroup $(n=103)$.

As mentioned above, differences in severity between treatment groups could have occurred due to masked residual confounders, and could participate to explain our results.

It would have been of interest to distinguish a subgroup of ICS users among our patients to observe the impact of ICS on outcomes. However, the number of non-ICS users was too low to allow robust analyses. 


\section{Conclusion}

In this "real-life" cohort of patients hospitalized for COPD, open triple therapy was not associated with improved outcomes compared with dual therapy in terms of persistence. Possibly, as a result of this poor compliance and the chosen design, we did not see any difference in terms of exacerbations. Our study results may be extrapolated to the whole French COPD population of moderate to high severity after hospitalization for an exacerbation, keeping in mind the complexity of assessing COPD severity in claims databases.

Finally, it would be of interest to repeat this study as fixed triple therapy are now available in a single inhaler: this could have an impact on adherence to treatment, and possibly on exacerbations. ${ }^{42,43}$

\section{Abbreviations}

EGB, Echantillon Généraliste des Bénéficiaires; FDC, fixed-dose combination; GP, general practitioner; HRU, health care resource use; ICD-10, International Classification of Diseases 10th Version; ICS, inhaled corticosteroid; LABA, long-acting beta-agonist; LAMA, longacting muscarinic antagonist; LTD, long-term disease; NIV, non-invasive ventilation; NS, non-significant; OCS, oral corticosteroids; PMSI, programme de médicalisation des systèmes d'information (French Diagnosis Related Groupbased medical information system); PFT, pulmonary function testing; SABA, short-acting beta-agonist; SAMA, short-acting muscarinic antagonist.

\section{Acknowledgments}

We thank the French National Health Service (Caisse Nationale de l'Assurance Maladie) and the National Institute of Health Data (Institut National des Données de Santé) for providing data. The study was funded by Chiesi SAS.

\section{Disclosure}

EVG is Scientific Advisor of PELyon, he reports personal fees from PELyon, during the conduct of the study; personal fees from PELyon, outside the submitted work. MN, FD and MB (employees of PELyon) conducted the study through sponsorship by Chiesi SAS, and were not paid for manuscript development. NR reports grants and personal fees from Boehringer Ingelheim, Novartis, Pfizer and personal fees from Teva, GSK, AstraZeneca, Mundipharma, Cipla, Sanofi, Sandoz, 3M, Zambon and Chiesi. PD has received consulting fees, honoraria for lectures and/or research funding from AstraZeneca, Boehringer Ingelheim, Chiesi, GlaxoSmithKline, and Novartis during the last 3 years. He reports personal fees from Chiesi, during the conduct of the study; personal fees from Astra Zeneca, personal fees from Boehringer Ingelheim, personal fees from Chiesi, personal fees from GlaxoSmithKline, personal fees from Novartis, personal fees from Sanofi, outside the submitted work. BH received honorarium from Boehringer Ingelheim, Pfizer, Novartis, Teva, GSK, AstraZeneca and Chiesi for his participation in scientific committees or conferences. He reports personal fees from Chiesi, during the conduct of the study; personal fees from GSK, personal fees from Boehringer Ingelheim, personal fees from Novartis, outside the submitted work. HP received honorarium from Boehringer Ingelheim, Novartis, Teva, GSK, AstraZeneca and Chiesi for his participation in scientific committees or conferences, is on the board for Chiesi and Novartis, and received an invitation to 2019 American Thoracic Society International Conference in Arizona, USA. GD received research funding from BTG/PneumRx and received honorarium from Boehringer Ingelheim, AstraZeneca, Chiesi, Novartis, BTG/PneumRx for his participation in scientific committees or conferences. He reports personal fees from Chiesi, during the conduct of the study; personal fees from AstraZeneca, personal fees from Boehringer Ingelheim, personal fees from BTG/PneumRx, and personal fees from Nuvaira, outside the submitted work. The authors report no other conflicts of interest in this work.

\section{References}

1. Mannino DM. Epidemiology and global impact of chronic obstructive pulmonary disease. Semin Respir Crit Care Med. 2005;26(2):204-210. doi:10.1055/s-2005-869539

2. Vogelmeier CF, Criner GJ, Martinez FJ, et al. Global strategy for the diagnosis, management, and prevention of chronic obstructive lung disease 2017 report: GOLD executive summary. Eur Respir J. 2017;49:3. doi:10.1183/13993003.00214-2017

3. Diaz-Guzman E, Mannino DM. Epidemiology and prevalence of chronic obstructive pulmonary disease. Clin Chest Med. 2014;35 (1):7-16. doi:10.1016/j.ccm.2013.10.002

4. Blanco I, Diego I, Bueno P, et al. Geographical distribution of COPD prevalence in Europe, estimated by an inverse distance weighting interpolation technique. Int $J$ Chron Obstruct Pulmon Dis. 2018;13:57-67. doi:10.2147/COPD.S150853

5. Roche N, Dalmay F, Perez T, et al. Impact of chronic airflow obstruction in a working population. Eur Respir J. 2008;31(6):1227-1233. doi:10.1183/09031936.00089607

6. INSERM. Bronchopneumopathie chronique obstructive (BPCO); 2014. Available from: http://www.inserm.fr/layout/set/print/thema tiques/sante-publique/dossiers-d-information/bronchopneumopathiechronique-obstructive-bpco. Accessed July 10, 2019. 
7. Martin-Latry K, Begaud B. Pharmacoepidemiological research using French reimbursement databases: yes we can! Pharmacoepidemiol Drug Saf. 2010;19(3):256-265. doi:10.1002/pds.1912

8. Tuppin P, Rudant J, Constantinou P, et al. Value of a national administrative database to guide public decisions: from the systeme national d'information interregimes de l'Assurance Maladie (SNIIRAM) to the systeme national des donnees de sante (SNDS) in France. Rev Epidemiol Sante Publique. 2017;65(Suppl 4):S149S167. doi:10.1016/j.respe.2017.05.004

9. Calverley PM, Anderson JA, Celli B, et al. Salmeterol and fluticasone propionate and survival in chronic obstructive pulmonary disease. $N$ Engl J Med. 2007;356(8):775-789. doi:10.1056/NEJMoa063070

10. Decramer M, Celli B, Kesten S, Lystig T, Mehra S, Tashkin DP. Effect of tiotropium on outcomes in patients with moderate chronic obstructive pulmonary disease (UPLIFT): a prespecified subgroup analysis of a randomised controlled trial. Lancet. 2009;374 (9696):1171-1178. doi:10.1016/S0140-6736(09)61298-8

11. Miravitlles M, D’Urzo A, Singh D, Koblizek V. Pharmacological strategies to reduce exacerbation risk in COPD: a narrative review. Respir Res. 2016;17(1):112. doi:10.1186/s12931-016-0425-5

12. Cramer JA, Roy A, Burrell A, et al. Medication compliance and persistence: terminology and definitions. Value Health. 2008;11 (1):44-47. doi:10.1111/j.1524-4733.2007.00213.x

13. Cramer JA, Bradley-Kennedy C, Scalera A. Treatment persistence and compliance with medications for chronic obstructive pulmonary disease. Can Respir J. 2007;14(1):25-29. doi:10.1155/2007/161652

14. Direction Générale de la Santé. Etude épidémiologique sur la BPCO: Synthèse. Ministère de la Santé, Paris, France; 2007.

15. Mueller S, Wilke T, Bechtel B, Punekar YS, Mitzner K, Virchow JC. Non-persistence and non-adherence to long-acting COPD medication therapy: a retrospective cohort study based on a large German claims dataset. Respir Med. 2017;122:1-11. doi:10.1016/ j.rmed.2016.11.008

16. Jebrak G. [COPD routine management in France: are guidelines used in clinical practice?] Rev Mal Respir. 2010;27(1):11-18. doi:10.1016/ j.rmr.2009.08.002

17. Roche N, Lepage T, Bourcereau J, Terrioux P. Guidelines versus clinical practice in the treatment of chronic obstructive pulmonary disease. Eur Respir J. 2001;18(6):903-908.

18. Yawn BP, Suissa S, Rossi A. Appropriate use of inhaled corticosteroids in COPD: the candidates for safe withdrawal. NPJ Prim Care Respir Med. 2016;26:16068. doi:10.1038/npjpcrm.2016.68

19. Breekveldt-Postma NS, Koerselman J, Erkens JA, Lammers JW, Herings RM. Enhanced persistence with tiotropium compared with other respiratory drugs in COPD. Respir Med. 2007;101(7):13981405. doi:10.1016/j.rmed.2007.01.025

20. Qian J, Simoni-Wastila L, Rattinger GB, et al. Association between depression and maintenance medication adherence among Medicare beneficiaries with chronic obstructive pulmonary disease. Int $J$ Geriatr Psychiatry. 2014;29(1):49-57. doi:10.1002/gps.3968

21. Simoni-Wastila L, Wei YJ, Qian J, et al. Association of chronic obstructive pulmonary disease maintenance medication adherence with all-cause hospitalization and spending in a Medicare population. Am J Geriatr Pharmacother. 2012;10(3):201-210. doi:10.1016/j. amjopharm.2012.04.002

22. Agh T, Inotai A, Meszaros A. Factors associated with medication adherence in patients with chronic obstructive pulmonary disease. Respiration. 2011;82(4):328-334. doi:10.1159/000324453

23. Albrecht JS, Park Y, Hur P, et al. Adherence to maintenance medications among older adults with chronic obstructive pulmonary disease. The role of depression. Ann Am Thorac Soc. 2016;13(9):1497-1504. doi:10.1513/AnnalsATS.201602-136OC

24. Cecere LM, Slatore CG, Uman JE, et al. Adherence to long-acting inhaled therapies among patients with chronic obstructive pulmonary disease (COPD). COPD. 2012;9(3):251-258. doi:10.3109/154125 55.2011 .650241
25. Huetsch JC, Uman JE, Udris EM, Au DH. Predictors of adherence to inhaled medications among Veterans with COPD. J Gen Intern Med. 2012;27(11):1506-1512. doi:10.1007/s11606-0122130-5

26. Laforest L, Licaj I, Devouassoux G, Hartwig S, Marvalin S, Van Ganse E. Factors associated with early adherence to tiotropium in chronic obstructive pulmonary disease. Chron Respir Dis. 2013;10 (1):11-18. doi:10.1177/1479972312464245

27. Yu AP, Guerin A, Ponce de Leon D, et al. Therapy persistence and adherence in patients with chronic obstructive pulmonary disease: multiple versus single long-acting maintenance inhalers. $J$ Med Econ. 2011;14(4):486-496. doi:10.3111/13696998.2011. 594123

28. Detournay B, Pribil C, Fournier M, et al. The SCOPE study: healthcare consumption related to patients with chronic obstructive pulmonary disease in France. Value Health. 2004;7(2):168-174. doi:10.1111/j.1524-4733.2004.72329.x

29. Huchon G, Crochard A, Vergnenegre A, et al. Prs2 cost of Chronic Bronchitis $(\mathrm{Cb})$ and Chronic Obstructive Pulmonary Disease (Copd) in France: the Broncheco study. Value Health. 2004;7:6.

30. Laurendeau C, Chouaid C, Roche N, Terrioux P, Gourmelen J, Detournay B. [Management and costs of chronic pulmonary obstructive disease in France in 2011]. Rev Mal Respir. 2015;32(7):682-691. doi:10.1016/j.rmr.2014.10.731

31. Pasquale MK, Sun SX, Song F, Hartnett HJ, Stemkowski SA. Impact of exacerbations on health care cost and resource utilization in chronic obstructive pulmonary disease patients with chronic bronchitis from a predominantly Medicare population. Int J Chron Obstruct Pulmon Dis. 2012;7:757-764. doi:10.21 47/COPD.S36997

32. Punekar YS, Landis SH, Wurst K, Le H. Characteristics, disease burden and costs of COPD patients in the two years following initiation of long-acting bronchodilators in UK primary care. Respir Res. 2015;16:141. doi:10.1186/s12931-015-0295-2

33. Davis JR, Wu B, Kern DM, et al. Impact of nonadherence to inhaled corticosteroid/LABA therapy on COPD exacerbation rates and healthcare costs in a commercially insured US population. Am Health Drug Benefits. 2017;10(2):92-102.

34. Khakban A, Sin DD, FitzGerald JM, et al. Ten-year trends in direct costs of COPD: a population-based study. Chest. 2015;148(3):640646. doi:10.1378/chest.15-0721

35. Khdour MR, Hawwa AF, Kidney JC, Smyth BM, McElnay JC. Potential risk factors for medication non-adherence in patients with chronic obstructive pulmonary disease (COPD). Eur J Clin Pharmacol. 2012;68(10):1365-1373. doi:10.1007/s00228-012-1279-5

36. Vetrano DL, Bianchini E, Onder G, et al. Poor adherence to chronic obstructive pulmonary disease medications in primary care: role of age, disease burden and polypharmacy. Geriatr Gerontol Int. 2017;17 (12):2500-2506. doi:10.1111/ggi.13115

37. Sriram KB, Percival M. Suboptimal inhaler medication adherence and incorrect technique are common among chronic obstructive pulmonary disease patients. Chron Respir Dis. 2016;13(1):13-22. doi:10.1177/1479972315606313

38. Laforest L, Denis F, Van Ganse E, et al. Correlates of adherence to respiratory drugs in COPD patients. Prim Care Respir J. 2010;19 (2):148-154. doi:10.4104/pcrj.2010.00004

39. Buhl R, Criee CP, Kardos P, et al. Dual bronchodilation vs triple therapy in the "real-life" COPD DACCORD study. Int J Chron Obstruct Pulmon Dis. 2018;13:2557-2568. doi:10.2147/COPD.S169958

40. Bourbeau J, Ernst P, Cockcoft D, Suissa S. Inhaled corticosteroids and hospitalisation due to exacerbation of COPD. Eur Respir J. 2003;22(2):286-289.

41. Molimard M, Raherison C, Lignot S, et al. Chronic obstructive pulmonary disease exacerbation and inhaler device handling: reallife assessment of 2935 patients. Eur Respir J. 2017;49:2. doi:10.1183/13993003.01794-2016 
42. Singh D, Papi A, Corradi M, et al. Single inhaler triple therapy versus inhaled corticosteroid plus long-acting $\beta 2$-agonist therapy for chronic obstructive pulmonary disease (TRILOGY): a double-blind, parallel group, randomised controlled trial. Lancet. 2016;388(10048):963973. doi:10.1016/S0140-6736(16)31354-X
43. Lipson DA, Barnhart F, Brealey N, et al. Once-daily single-inhaler triple versus dual therapy in patients with COPD. $N$ Engl J Med. 2018. doi:10.1056/NEJMoa1713901 


\section{Supplementary materials}

Table SI Characteristics of non-matched patients and matched patients on dual or triple therapy

\begin{tabular}{|c|c|c|c|c|}
\hline & \multicolumn{2}{|c|}{ Non-matched patients $(n=440)$} & \multicolumn{2}{|c|}{ Matched patients $(=I, 060)$} \\
\hline & $\begin{array}{l}\text { Dual therapy } \\
(n=3 \mid 6)\end{array}$ & $\begin{array}{l}\text { Triple therapy } \\
(n=124)\end{array}$ & $\begin{array}{l}\text { Dual therapy } \\
(n=530)\end{array}$ & $\begin{array}{l}\text { Triple therapy } \\
(n=530)\end{array}$ \\
\hline Men (\%) & 31.3 & 74.2 & 65.8 & 65.3 \\
\hline \multicolumn{5}{|c|}{ Age class (in the year prior to index date), $n(\%)$} \\
\hline $45-54$ & 8.2 & 15.3 & 12.8 & 10.5 \\
\hline $55-64$ & 12.0 & 33.9 & 24.5 & 23.9 \\
\hline $65-74$ & 22.5 & 27.4 & 26.1 & 30.9 \\
\hline $75-79$ & 14.2 & 12.1 & 14.3 & 15.3 \\
\hline$\geq 80$ & 43.0 & 11.2 & 22.3 & 19.2 \\
\hline \multicolumn{5}{|c|}{$\begin{array}{l}\text { Number of other treatments for COPD }{ }^{a} \text { (in the year } \\
\text { prior to index date) }\end{array}$} \\
\hline 0 & 38.9 & 34.7 & 33.0 & 29.8 \\
\hline I & 32.3 & 36.3 & 39.8 & 38.7 \\
\hline 2 & 21.8 & 19.4 & 20.0 & 23.4 \\
\hline 3 & 6.3 & 8.1 & 6.8 & 7.5 \\
\hline$\geq 4$ & 0.6 & 1.6 & 0.4 & 0.6 \\
\hline \multicolumn{5}{|c|}{ Number of exacerbations (in the year prior to index date) } \\
\hline 1 & 23.1 & 23.4 & 27.0 & 23.0 \\
\hline 2 & 34.2 & 30.6 & 26.4 & 29.8 \\
\hline 3 & 18.7 & 16.9 & 22.1 & 21.9 \\
\hline 4 & 15.2 & 15.3 & 14.9 & 15.1 \\
\hline 5 & 6.6 & 6.5 & 6.6 & 6.0 \\
\hline 6 & 1.6 & 4.8 & 2.5 & 3.2 \\
\hline$\geq 7$ & 0.6 & 2.4 & 0.6 & 0.9 \\
\hline \multicolumn{5}{|c|}{ Comorbidities (in the year prior to index date) (\%) } \\
\hline Cardiovascular diseases & 83.5 & 60.5 & 72.6 & 73.0 \\
\hline Depression & 31.3 & 11.3 & 19.2 & 21.1 \\
\hline Cancers & 12.7 & 12.1 & 16.4 & 18.5 \\
\hline Diabetes (type I and type 2) & 26.9 & 9.7 & 18.9 & 18.7 \\
\hline Dead (in the year following inclusion) (\%) & 10.4 & 5.6 & 10.0 & 10.0 \\
\hline
\end{tabular}

Note: ${ }^{a}$ Included SABA, SAMA, SABA/SAMA FDC and xanthines.

Table S2 Sensitivity analysis: percentage of non-persistent patients at 12 months after index date, where non-persistence was defined as a treatment discontinuation of at least 61 instead of 91 consecutive days

\begin{tabular}{|l|l|l|}
\hline & Number of studied patients & Number (\%) of non-persistent patients \\
\hline Dual therapy & 103 & $56(56.3 \%)$ \\
Triple therapy & 103 & $66(64.1 \%)$ \\
\hline
\end{tabular}




\section{Publish your work in this journal}

The International Journal of COPD is an international, peer-reviewed journal of therapeutics and pharmacology focusing on concise rapid reporting of clinical studies and reviews in COPD. Special focus is given to the pathophysiological processes underlying the disease, intervention programs, patient focused education, and self management protocols. This journal is indexed on PubMed Central, MedLine and CAS. The manuscript management system is completely online and includes a very quick and fair peer-review system, which is all easy to use. Visit http://www.dovepress.com/testimonials.php to read real quotes from published authors. 